\title{
BMJ Open The Women and Their Children's Health (WaTCH) study: methods and design of a prospective cohort study in Louisiana to examine the health effects from the BP oil spill
}

\author{
Edward S Peters, ${ }^{1}$ Ariane L Rung, ${ }^{1}$ Megan H Bronson, ${ }^{1}$ Meghan M Brashear, ${ }^{1}$ \\ Lauren C Peres, ${ }^{2}$ Symielle Gaston, ${ }^{3}$ Samaah M Sullivan, ${ }^{4}$ Kate Peak, ${ }^{1}$ \\ David M Abramson, ${ }^{5}$ Elizabeth T H Fontham, ${ }^{1}$ Daniel Harrington, ${ }^{6}$ Evrim Oral, ${ }^{7}$ \\ Edward J Trapido ${ }^{1}$
}

To cite: Peters ES, Rung AL, Bronson MH, et al. The Women and Their Children's Health (WaTCH) study: methods and design of a prospective cohort study in Louisiana to examine the health effects from the BP oil spill. BMJ Open 2017;7:e014887. doi:10.1136/ bmjopen-2016-014887

- Prepublication history for this paper is available online. To view these files please visit the journal online (http://dx.doi. org/10.1136/bmjopen-2016014887).

Received 24 October 2016 Revised 25 May 2017 Accepted 26 May 2017

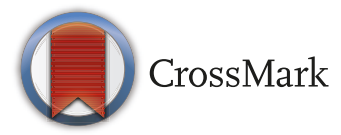

For numbered affiliations see end of article.

Correspondence to

Dr. Edward S Peters; epete1@ Isuhsc.edu

\section{ABSTRACT}

Purpose The Deepwater Horizon Oil Spill is the largest marine oil spill in US history. Few studies have evaluated the potential health effects of this spill on the Gulf Coast community. The Women and Their Children's Health (WaTCH) study is a prospective cohort designed to investigate the midterm to long-term physical, mental and behavioural health effects of exposure to the oil spill. Participants Women were recruited by telephone from pre-existing lists of individuals and households using an address-based sampling frame between 2012 and 2014. Baseline interviews obtained information on oil spill exposure, demographics, physical and mental health, and health behaviours. Women were also asked to provide a household roster, from which a child between 10 and 17 years was randomly selected and recruited into a child substudy. Telephone respondents were invited to participate in a home visit in which blood samples, anthropometrics and neighbourhood characteristics were measured. A follow-up interview was completed between 2014 and 2016.

Findings to date 2852 women completed the baseline interview, 1231 of whom participated in the home visit, and 628 children participated in the child's health substudy. The follow-up interview successfully reinterviewed 2030 women and 454 children.

Future plans WaTCH continues to conduct follow-up surveys, with a third wave of interviews planned in 2017. Also, we are looking to enhance the collection of spatially related environmental data to facilitate assessment of health risks in the study population. In addition, opportunities to participate in behavioural interventions for subsets of the cohort have been initiated. There are ongoing studies that examine the relationship between genetic and immunological markers with mental health.

\section{INTRODUCTION}

\section{Deepwater Horizon Oil Spill}

Oil spills result in profound environmental pollution and economic consequences for

\section{Strengths and limitations of this study}

- Involved a unique vulnerable population repeatedly traumatised by natural and technological disasters.

- Used a longitudinal prospective design with active retention and follow-up augmented through community advisory members

- Conducted systematic social observation of neighbourhood conditions

- Subjects challenging to enumerate and sample population overburdened by research due to their experience of numerous disasters, resulting in some degree of mistrust of population research studies.

- Indirect surrogate measurement of oil spill exposure constructed after the fact based on self-reported subjective measures.

communities in the affected areas. Populations near oil spills are potentially exposed to hazardous components of crude oil, including volatile organic carbons and heavy metals. ${ }^{1}$ On 20 April 2010, the British Petroleum (BP)-operated Deepwater Horizon drilling rig exploded 49 miles off the Mississippi River Delta in Louisiana, killing 11 workers and burning for approximately 36 hours before sinking. ${ }^{2}$ Nearly 210 million gallons of crude oil spilled into the Gulf of Mexico over an area up to 68000 square miles before the sea-floor wellhead was finally capped on 15 July 2010, after many failed attempts. ${ }^{3}$ The Deepwater Horizon Oil Spill (DHOS) was the largest accidental marine oil spill in the history of the US petroleum industry, dwarfing all prior oil tanker spills in magnitude and impact on the environment and causing extensive damage to marine 
and wildlife habitats. It contaminated over 1000 miles of beach and marsh shoreline from Texas to Florida and threatened the viability of the northern Gulf's commercial fishing and tourism industries. ${ }^{45} \mathrm{BP}$ used controlled burns, releasing 1.84 million gallons of dispersant chemicals into the ecosystem to break up the crude oil, and employed several thousand workers and volunteers to participate in clean-up activities. ${ }^{26}$ Despite these efforts, the Gulf Coast region was severely impacted by the DHOS, with damage to the environment, effects to both the tourism and fishing industries, and threats to the physical and mental well-being of residents, clean-up workers and volunteers. The impact of the oil spill was of primary concern among seven southeast Louisiana parishes Orleans, St Bernard, Jefferson, Plaquemines, Lafourche, Terrebonne and St Mary - due to their geographical proximity to the wellhead, low elevation and economic reliance on fishing and other marine activities. ${ }^{2}$

\section{Oil spills and health}

There has been little research on the long-term health effects resulting from oil spills, despite the fact that from the early 1970 s to 2010 , there have been over 350 spills of more than 700 tons of oil, and many of these spills directly impacted land and affected coastal communities. ${ }^{7}$ The small number of studies that have been conducted to date on the human health impact of oil spills, dispersants and airborne particulate matter has focused primarily on the immediate physical, physiological and psychological effects. ${ }^{8-10}$ Crude oil and dispersants contain many toxic components, including a wide range of aromatic/aliphatic hydrocarbons, hydrogen sulfide gas, heavy metals and sulfonic acid. Exposure to these toxic components may result in a variety of adverse physiological effects in the immediate aftermath of an oil spill, including respiratory irritation, cough and shortness of breath, and central nervous system depression. ${ }^{811} 12$ Human health can also be indirectly affected by the DHOS through social and economic disruption. ${ }^{13-18}$ Many Gulf Coast residents are dependent on local fishing and tourism for their source of income, and these industries were severely affected by the DHOS and its destruction of the surrounding ecosystem. ${ }^{219}$ The ensuing financial liability from oil spills often negatively impacts the mental and psychosocial wellbeing of an entire household and may possibly manifest as behavioural and physical health disorders. ${ }^{18}{ }^{20}$ A review article by Aguilera $e t a l^{8}$ examined several epidemiological studies that explored population health effects after exposure to oil spills, finding a consistent association between oil spill exposure and neurological, respiratory, dermal and mental health effects. A more recent review concluded that mental and physical/physiological effects from oil spills may persist for years. ${ }^{12}$ The DHOS has often been compared with the second largest maritime oil spill in the USA, the Exxon Valdez oil spill. In 1989, the tanker Exxon Valdez ran aground in Prince William Sound, Alaska, and spilled thousands of barrels of oil onto the coast, which has had substantial impact on the health of surrounding communities. ${ }^{21}{ }^{22}$ Several studies have examined the health effects from the Exxon Valdez oil spill, observing that oil spill-exposed individuals reported a higher degree of economic disruption and an increase in adverse mental health outcomes, including stress, anxiety and depression compared with those without spill exposure. ${ }^{22}{ }^{23}$ Another study conducted 2 years after the Prestige oil spill observed that fishermen who had participated in the clean-up efforts were more likely to report respiratory problems and exhibit chromosomal alterations than those of the same communities who did not participate in the clean-up activities. ${ }^{24}$ To date, only a few studies have examined the human health effects associated with the DHOS. ${ }^{25}{ }^{26}$ Peres $e t a l^{27}$ studied the physical health of women in southeast Louisiana after the DHOS and observed a higher frequency of headaches, shortness of breath, watery, burning, itchy eyes, skin rash and cough among women who reported higher DHOS exposures compared with non-exposed or low-DHOS-exposed women. An additional study examined the mental health effects of individuals residing in southern Louisiana after the DHOS, reporting that disruption of the family and work environment by the DHOS was associated with negative mental health outcomes, especially anxiety and depression. ${ }^{28}$ A study in Alabama and Florida observed that affected communities were more likely to report stress, anxiety and depression. ${ }^{25}$

\section{Defining oil spill exposure}

Even though there have been several oil spills around the world, with fewer studies examining their impacts on individual and community health, a consistent, reliable and valid measurement of an individual's oil spill exposure has not yet been established or used throughout the disaster literature. ${ }^{12}$ Defining what constitutes oil spill exposure is a challenging and crucial step in studying and understanding the impact oil spills can have on human health and well-being. In addition, traditional epidemiological studies examining health-related effects of oil spills have focused mainly on clean-up workers. ${ }^{829}$ Although clean-up workers are the most likely persons to be directly exposed to the crude oil, massive oil spills such as the DHOS have a far-reaching effect on residents of surrounding communities. In particular, children are vulnerable and susceptible to long-term mental and physical health effects from oil spills and other disasters. ${ }^{30}{ }^{31}$ In the wake of the DHOS, the Institute of Medicine (IOM) called for more research to study the physiological, psychological and behavioural effects of oil spills. ${ }^{32}$

Most epidemiological observational studies established after the DHOS event were initiated 1-2 years after the spill occurred and were therefore unable to capture oil spill exposure information at the time of the spill from participants. Therefore, they required some form of retrospective assessment. Exposures may be directly measured using sophisticated equipment or assays, or they can be inferred through questionnaires asking about the presence of the environmental agent of interest. With 
respect to the oil spill, exposure was not simply a single agent in a defined setting. Rather it was long-lasting, widespread and a complex mixture of unspecified chemical, physical, environmental, economic and emotional experiences individuals in the community faced. Sometimes, a complex mix of exposures occurring in a broad geographical setting may be considered as valid as specific measures of a single agent when being considered in the context of public health setting. ${ }^{33}$ Previous oil spill studies have demonstrated this approach. Most relevant to the present study is the approach adopted by Palinkas $e t a l^{34}$ in studying the Exxon Valdez oil spill. They employed a framework used in previous disaster research whereby study participants were classified based on their exposure to the oil spill and subsequent events using a series of questions about physical, economic and behavioural impacts. This approach has been used in numerous studies that examine the environmental impact of oil spill exposures on communities and individuals, and is adopted here.

\section{Study objective}

The currently available literature is suggestive of increased adverse physical and mental health outcomes associated with oil spills, although the evidence is often limited to those with the greatest exposure, such as clean-up workers, and may not be generalisable to the broader impacted community. In response to the $\mathrm{IOM}^{32}$ report calling for studies of health effects from the DHOS, we established the Women and Their Children's Health (WaTCH) study with the goal of improving understanding of community effects from the oil spill. This study focuses on the health of adult women and their children residing in the most heavily affected areas of Louisiana. Women in particular represent a vulnerable yet influential population. They are often central to decision-making processes within families, especially with respect to decisions regarding health, support, diet and child-rearing. The purpose of this paper is to describe the study design, challenges in recruitment and the study population of a cohort of women and children from southeast Louisiana.

\section{COHORT DESCRIPTION \\ WaTCH organisation and administration}

The WaTCH study is a prospective cohort study conducted by the Louisiana State University Health Sciences (LSUHSC-NO) School of Public Health (SPH) in collaboration with investigators from New York University and Colorado State University. The primary funding for the study came from the National Institute of Environmental Sciences (NIEHS) Deepwater Horizon Research Consortia programme, ${ }^{35}$ which was a 5-year, $\$ 25.2$ million effort creating community-university partnerships aimed at addressing the health effects stemming from the oil spill. The WaTCH fieldwork was conducted in Louisiana by investigators and study staff located at the LSUHSC-NO SPH. Data collection and management was centralised in the SPH Epidemiology programme. The study leadership team was represented by the Co-Principal investigators, the Co-Investigators and a community liaison. As mandated by the NIEHS Deepwater Consortia programme, a community advisory board (CAB) was convened to provide input on the recruitment of subjects and dissemination of study findings. All WaTCH protocols were approved by the institutional review boards (IRBs) at LSUHSC-NO, New York University and Colorado State University. This study was also awarded a Certificate of Confidentiality from the National Institutes of Health, which helps researchers protect the privacy of human research participants enrolled in sensitive health-related research. These certificates protect against compulsory legal demands, such as court orders and subpoenas, for identifying information or identifying characteristics of a research participant. ${ }^{36}$ The WaTCH study focuses on community and individual resiliency, mental health and physical health. WaTCH consists of two major projects: (1) an examination of the acute and long-term human health effects of the DHOS and its clean-up among adult women in the community; and (2) an examination of how the effects of the oil spill influence the emotional well-being of children and adolescents.

\section{Study design, subject identification, recruitment and enrolment}

Our overall strategy was to establish a cohort of women and their children residing in the seven most heavily affected parishes (counties) in southeast Louisiana: Orleans, St Bernard, Jefferson, Plaquemines, Lafourche, Terrebonne and St Mary. This defined region, shown in figure 1, includes a population of approximately 725000 people. All participants arose from this primary study base.

\section{Inclusion}

Eligibility requirements for the adult women initially included being between 18 and 80 years of age; ability to complete the study interview in English; absence of cognitive impairment; and residence in one of the study parishes on 20 April 2010. We excluded women who were participating in the NIEHS GuLF Study, an intramural study investigating health effects among DHOS clean-up workers. ${ }^{29}$ After approximately 6 months, we lowered the upper age limit to 50 years of age to better recruit a greater proportion of women with eligible adolescent children. The population of adult women was enumerated from pre-existing lists of individuals and households using an address-based sampling frame provided by Marketing Systems Group (MSG). Address-based sampling uses the US Postal Service's Computerized Delivery Sequence file (CDS), which MSG licenses. The CDS database contains over 135 million residential addresses and provides nearly $100 \%$ coverage of all households in the USA. The CDS file contains a variety of address types, including city style, rural routes, post office boxes, seasonal, vacant and drop points. Sampling frames can be defined by any level of geography (postal or census) from census block up to 


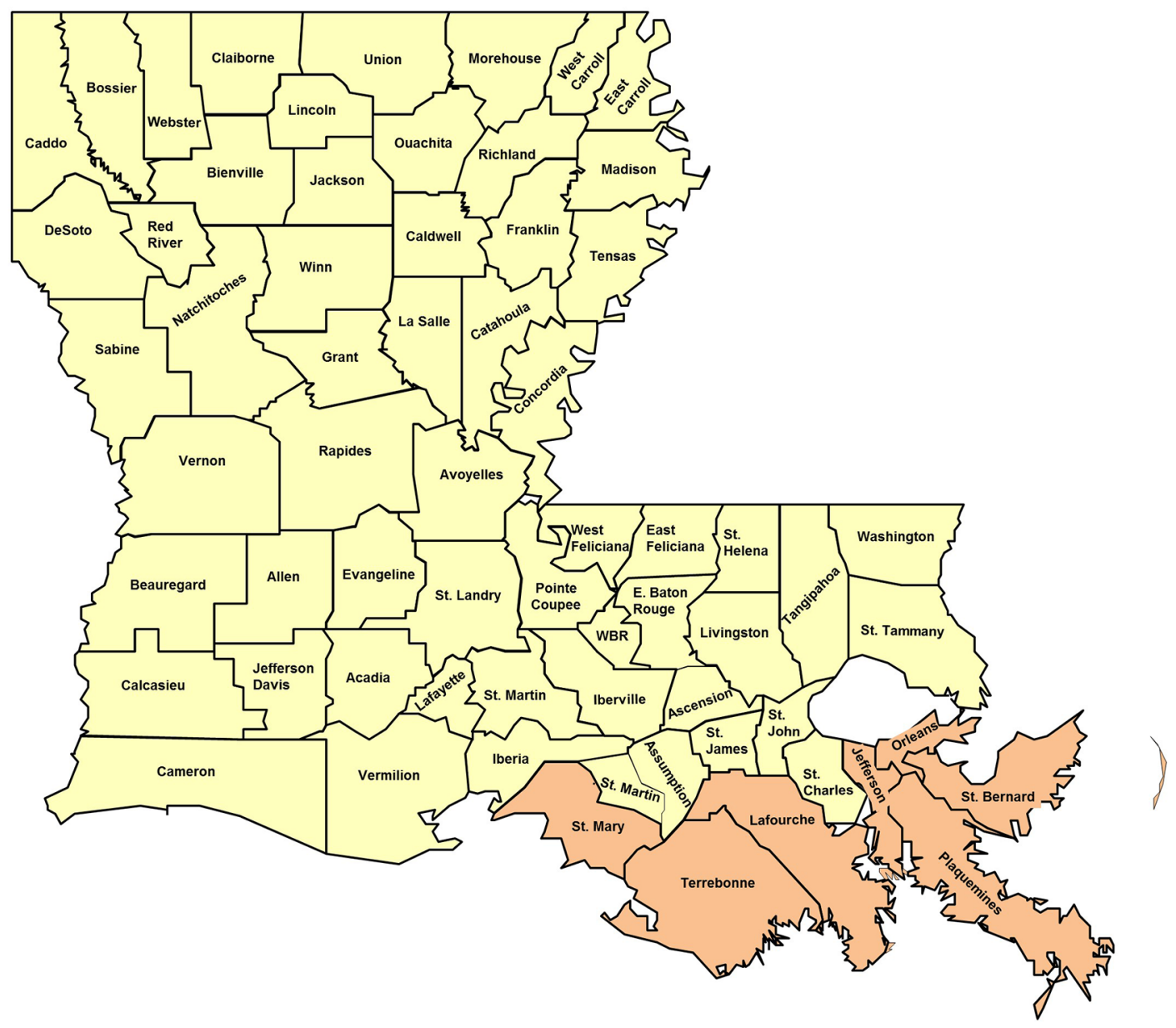

Figure 1 Map of Louisiana with study base shaded.

national. Additionally, a combination of address types can be targeted to satisfy the requirements of the research project. Household characteristics of age and gender were added to the ABS sample to further restrict the frame. Cellular telephone samples were not included due to limited availability of targeted numbers and high cost.

We initially conducted two-stage cluster sampling to ensure that we undersampled individuals from Orleans and Jefferson parishes, the two larger, more urban parishes. We specifically undersampled the northern, urban portions of these parishes because significant oil spill exposure was unlikely. MSG provided a sampling frame of approximately 48000 valid addresses with phone numbers. Other than the two urban parishes, we sought to assure proportional representation relative to the 2010 census in the cohort across all census tracts in the five-parish region. We also enrolled additional women referred to the study through friends, neighbours, other parties or direct marketing. We anticipated that a number of interested volunteers would hear about the study through community efforts to enhance recruitment. We had a CAB to assist recruitment through several community engagement and community outreach recruitment activities. Women who contacted us through the study website or by calling a toll free number were considered for the study if they met the eligibility criteria described above.

Recruitment began when potential female participants were mailed an introductory letter describing the nature of the study (telephone interview, home visit, blood, urine collection and remuneration) and inviting them to participate. This was followed 1-2 weeks later by a screening recruitment telephone call from a trained interviewer who ascertained the availability of an eligible adult woman residing at the address, provided further detail concerning the investigation and formally requested her participation. If we did not have a valid phone number for the potential participant, another letter was sent requesting that she either call a toll free number or use a secure web portal indicating her willingness to participate in the study. Interviews were conducted by the primary study staff at the LSUHSC-NO SPH in New Orleans as well by the LSU Public Policy Research Lab in Baton Rouge. All interviewers were trained and quality control measures were implemented to assure standardisation.

Interviewers were instructed to call each number at least 12 times. Call attempts were also repeated after contact information was updated using a commercial tracing 
service (Accurint). Between August of 2012 and June of 2014, calls were made to 42649 telephone numbers in an attempt to reach potentially eligible women for participation in the WaTCH study.

\section{Telephone interview}

Women who agreed to participate and provided verbal consent (a waiver of documentation of informed consent for the telephone interview portion of the study was granted by the IRB) were administered a computer-assisted telephone interview. Study data were collected and managed using REDCap (Research Electronic Data Capture) electronic data capture tools hosted at the Epidemiology Data Center at the LSUHSC SPH. REDCap is a secure, web-based application designed to support data capture for research studies, providing (1) an intuitive interface for validated data entry; (2) audit trails for tracking data manipulation and export procedures; (3) automated export procedures for seamless data downloads to common statistical packages; and (4) procedures for importing data from external sources. ${ }^{37}$ The questionnaire included detailed questions on demographic characteristics, physical and mental health history, exposure to the oil spill or its clean-up, medication use, lifestyle characteristics such as diet, smoking, alcohol consumption, physical activity, occupational history, and exposure to prior hurricanes and other exposure information. There were also questions regarding healthcare access, social support, social capital, resource loss, financial or economic hardship and other measures of resiliency. Reasons for declining participation were recorded. Many of the questionnaire instruments employed were previously validated and publicly available (eg, the NIEHS GuLF study or PhenX Toolkit) or obtained from other epidemiological studies or national surveys. ${ }^{29} 38$

\section{Home visit and biospecimen collection}

All participants were asked at the end of the baseline telephone interview to participate in a home visit where biological samples (blood or saliva and urine) and anthropometric measures (height, weight, waist circumference and hip circumference) were going to be collected. If the study subject agreed to the home visit, the information was forwarded to an independent contractor responsible for the home visit. Certified medical assistants (CMAs) who could do both phlebotomy and interviewing (for the mother and child substudy described below) were recruited through DOCS Global, a clinical resourcing provider. The CMAs completed the home visits, with training, supervision and supplies provided centrally by the WaTCH study coordinators. Each participant provided written informed consent for the anthropometric measures and collection of biological specimens, as well as for documentation of the telephone interview. Each participant was asked to provide a blood sample; however, if she was unable or unwilling to do so, she was asked to give a saliva sample using an Oragene self-collection kit (DNA Genotek). If a participant did not wish to have a home visit but consented to give a saliva sample, an Oragene self-collection kit was mailed directly to the participant. The CMA obtained weight $(\mathrm{kg})$, height $(\mathrm{m})$ and hip and waist circumference $(\mathrm{cm})$ three times using a digital scale and tape measure. For each subject, the CMA collected approximately $16 \mathrm{cc}$ of blood (four $4 \mathrm{~mL}$ tubes) and $30 \mathrm{cc}$ of urine. The following blood samples were obtained: two lavender EDTA tubes for plasma and leucocytes; and two red top tubes with no additives for serum and clots. Collected samples were transported on ice to the LSUHSC SPH Laboratory within 24 hours of collection for processing and storage. Blood samples were processed to extract serum, plasma and buffy coat. Urine and aliquots of serum, plasma and buffy coat were stored long term at $-80^{\circ} \mathrm{C}$. Saliva samples were stored at room temperature according to standard protocol. DNA was extracted from cells contained in the buffy coat using the Qiagen QIAamp Blood Mini Kit and from saliva using the DNA Genotek prepIT-C2D kit. Extracted DNA was stored in $-20^{\circ} \mathrm{C}$. Participants in the study received remuneration for their time and effort. Remuneration was originally $\$ 25$ for a phone interview, $\$ 20$ for a home visit, $\$ 15$ for a mother interview and $\$ 15$ for a child interview. After approximately 6 months, the amount of remuneration to the adult women was increased to $\$ 40$ for phone interview and $\$ 25$ for anthropometrics and biospecimen collection.

\section{Neighbourhood audit}

Before the home visit, the CMA conducted a neighbourhood assessment of the immediate block face surrounding participants' homes. The neighbourhood audit was used to obtain an estimate of the amount of social disorder on the participants' street as one measure of environmental stress. The instrument has been previously validated and adapted from prior studies ${ }^{39}$ and included 25 items rating the block face and street of each participant's residence. Information was obtained on land use and condition, as well as on volume of traffic, condition of street, noise, smells, presence of abandoned cars, garbage/litter/ broken glass, graffiti and presence of recreational facilities.

\section{Child impact substudy}

Before terminating the adult telephone survey, women who reported having a child between the ages of 10 and 17 years of age living at home at the time of the oil spill were invited to participate in the child impact substudy. The interviewer described the child impact substudy and asked whether the respondent would be willing to have her child participate. Upon agreement to participate, one child per family between the ages of 10 and 17 years was randomly selected from among all the children aged 10-17years in the home. If the selected child was physically or mentally unable to participate, another child was randomly selected from within the household. A faceto-face interview was scheduled during a time in which the woman and selected child were both available for 
an interview. We strove to have this visit coincide with the women's home visit for biospecimen collection. If a woman refused to participate in the home visit for biospecimen collection yet had an eligible child, we offered her an opportunity to complete the mother and child portion as a telephone interview.

\section{Home visit for women and children}

Home visits for the participating adult women were handled as described above for consent and biospecimen collection. For those women with a participating child, additional parental consent and child assent were obtained by the CMA at the time of the home visit before the parent and child interviews started.

The mother and child interviews for the child impact substudy included (1) a 45 min interview of the mother or guardian of the child, including parent and household-level factors regarding the child's physical and emotional health, academic achievement, behaviour and development; household needs and resources; and neighbourhood characteristics to supplement the telephone survey; and 2) a 15 min interview of the child about his or her thoughts and feelings regarding the oil spill, coping strategies, hopelessness, stress and behaviour. The women were remunerated an additional $\$ 25$ for completing the child assessment interview, and children were given $\$ 25$. All in-home data collection for women and children was accomplished using iPads running the iForm application. iForm is a cloud-based mobile data collection platform that allows secure form-based data collection with or without internet connectivity. Global Positioning System (GPS) data acquisition of CMAs and study participant locations and residences also occurred.

\section{Quality control}

To ensure consistency, participant safety and confidentiality, CMAs were trained and activities were standardised and periodically reassessed during the study period. Interview and biological sample collection data were reviewed on an ongoing basis to identify process or procedure variation among study staff, and feedback was given when corrections were needed to maintain consistency.

In addition, the project manager randomly selected $10 \%$ of the study participants after telephone interviews, and study visits were completed to assess CMA performance and solicit feedback about the home visit.

\section{Follow-up survey}

A follow-up (wave II) telephone survey was implemented from September 2014 to June 2016. The follow-up questions reassessed information collected during the baseline phone interview, including demographics, physical and mental health, behaviours and other exposures. New modules were added including questions to assess the following personal characteristics: conservation and loss of resources, resiliency, social capital, perceived stress, life events and post-traumatic stress.
Women in the WaTCH study were recontacted for inclusion in the wave II follow-up. Each adult WaTCH participant received a letter describing the nature of the wave II questionnaire, followed by a telephone call from an LSUHSC-NO-based interviewer to ascertain the willingness of the participant to complete the follow-up survey. Interviewers called each number at least 12 times. The calling cycle was repeated after sending reminder post cards. Contact information was updated using Accurint. For completion of the wave II questionnaire, participants received $\$ 40$ for their time and effort.

For the children's substudy, brief follow-up telephone interviews were conducted with mothers and their children. Similar recontact approaches described above were attempted to locate mothers and their children. Child interview questions reassessed information collected during the baseline interview, including demographics, physical and mental health, social behaviours and school information. Mothers and children also each received $\$ 25$ for their time and effort.

\section{Cohort retention}

Participants receive annual newsletters, holiday cards and other mailings, including an annual reminder to update contact information either through the study website ( sph.lsuhsc.edu/watch) or by calling a toll free number. In addition to providing information about the study, these mailings keep the participant contact database up-to-date. It is anticipated that study participants will be followed by telephone interview every 2-3years dependent on the available research support funding.

\section{DHOS exposure}

To characterise exposure to the DHOS, the WaTCH study used six oil spill exposure questions that Palinkas et $a t^{23}$ developed for the 1989 Exxon Valdez oil spill and added three additional questions on the financial impact of the DHOS and the participant's experience in smelling the oil. Table 1 lists the WaTCH interview items used to assess potential exposures to the DHOS. Since these nine items were highly correlated with each other, we used a datadriven approach, exploratory factor analysis, to quantify exposure to the DHOS that fit the variance-covariance matrix of the observed variables, followed by a confirmatory factor analysis to test relations among indicator variables and latent variables.

\section{Response rate}

The response rate was defined using the American Association of Public Opinion Research's (AAPOR) standard definitions for surveys. ${ }^{40}$ It was defined as the number of complete interviews with respondents divided by the number of eligible respondents in the sample plus an estimated proportion of cases with unknown eligibility that may actually be eligible. Of the 42649 telephone numbers attempted, 16732 numbers were deemed ineligible (disconnected numbers, no woman at the telephone number, businesses and so on), and 22998 numbers were 
Table 1 DHOS exposure items asked of adult WaTCH participants in the telephone survey

\section{DHOS exposure items}

1. Did you work on any of the oil spill clean-up activities?

2. Are there any other ways that you came into physical contact with the oil from the spill or clean-up activities?

\section{Did you have any property that was lost or damaged} because of the oil spill or clean-up?

4. Did the oil spill cause any physical damage to the areas where you or other household members fish commercially?

\section{Has the oil spill directly affected the recreational hunting,} fishing or other activities of any members of this household?

6. Did you or anyone in your household lose any income due to disruption of employment or closing a business because of the oil spill?

\section{Compared with other residents in your community, were you:}

8. How would you rate the influence of the oil spill on your household's current financial situation?

\section{After the oil spill, could you smell the oil?}

9a. If yes, how strong was the smell?

\section{9b. If yes, how often could you smell it?}

\section{Answer choices}

Yes/No

Yes/No

\section{Yes/No}

Yes/No

Yes/No

Yes/No

Hit harder, affected about the same or affected less by the oil spill

Very negative, somewhat negative, somewhat positive, very positive or no influence

Yes/No

Not strong, a little strong, moderately strong, quite strong or extremely strong

None, a little of the time, some of the time, most of the time or all of the time

DOHS, Deepwater Horizon Oil Spill; WaTCH, Women and Their Children's Health study.

of unknown eligibility (never picked up, hung up before determination of eligibility). Sixty-seven were known to be eligible but refused to participate or were unable to be contacted. The final baseline (wave I) sample consisted of 2852 women who completed the telephone questionnaire. Therefore, the response rate was estimated as the number of complete interviews $(\mathrm{n}=2852)$ divided by the number of eligible respondents in the sample (those interviewed plus 67 who refused) plus the estimated proportion of cases with unknown eligibility that may actually be eligible. For this proportion, we used AAPOR's suggested estimate of about $15 \%$. Because we had almost 23000 cases of unknown eligibility (i.e., people in our sampling frame who we were unable to reach to even determine their eligibility much less consent them into the study), this meant an additional 3450 cases were included in the response rate denominator. Therefore, the overall response rate was $45 \%$. Our cooperation rate (number of interviews divided by number of interviews plus number of refusals) was $98 \%$.

\section{Statistical analysis}

We used summary statistics to show the demographic and exposure characteristics of surveyed women in waves I and II. Statistical analyses were performed using SAS V.9.4, except for the exploratory and confirmatory factor analyses, which were conducted using MPlus V.7 (Muthen \& Muthen, Los Angeles, California, USA).

\section{FINDINGS TO DATE}

\section{Subject accrual}

Between July 2012 and August 2014, 2852 women completed the baseline telephone interview. As described, the response and cooperation rates were $45 \%$ and $98 \%$, respectively. Individuals who volunteered for the study accounted for less than $5 \%$ of the wave I sample. There were 2788 women who completed the full interview, and 64 , considered partial interviews, completed over $50 \%$ of the questions but not the entire interview. The mean time from oil spill to the first telephone interview was 3.1 years. Of the 2852 women, 1231 women (43\%) participated in a home visit in which blood was successfully obtained from 1058 women $(37 \%)$ and urine from $1176(41 \%)$. In addition, 221 women (8\%) provided us a saliva sample through either the home visit or self-collection and overnight delivery. We identified and successfully recruited 628 children and their mothers.

\section{Baseline wave I subject demographic characteristics}

Table 2 presents the demographic characteristics of the 2852 women in the cohort. The mean age of the adult women was 45.7 years, and the majority of the study population was white $(56 \%)$, with $34 \%$ black and $6.3 \%$ other race; $3.5 \%$ chose not to report race. About a third of the women reported an annual prespill household income of less than $\$ 30000,28 \%$ of women reported currently drinking alcohol, and 20\% reported currently smoking. Approximately $70 \%$ reported having an education of 
Table 2 Baseline wave I demographic characteristics of the 2852 adult women in WaTCH

\begin{tabular}{|c|c|c|}
\hline & $\mathbf{N}$ & $\%$ \\
\hline & Mean & SD \\
\hline \multicolumn{3}{|l|}{ Interview type } \\
\hline Full & 2788 & 97.8 \\
\hline Partial & 64 & 2.2 \\
\hline Home visit & 1231 & 43.1 \\
\hline Time from spill to interview (years) & 3.1 & 0.38 \\
\hline \multicolumn{3}{|l|}{ Age (years) } \\
\hline 19-34 & 486 & 17.0 \\
\hline $35-49$ & 1525 & 53.5 \\
\hline $50-64$ & 589 & 20.7 \\
\hline $65+$ & 252 & 8.8 \\
\hline \multicolumn{3}{|l|}{ Race } \\
\hline Non-Hispanic white & 1604 & 56.2 \\
\hline Non-Hispanic black & 969 & 34.0 \\
\hline Other & 179 & 6.3 \\
\hline Unknown & 100 & 3.5 \\
\hline \multicolumn{3}{|l|}{ Marital status } \\
\hline Married/Living with partner & 1785 & 62.6 \\
\hline Never married & 498 & 17.5 \\
\hline Widowed/Divorced/Separated & 565 & 19.8 \\
\hline Unknown & 4 & 0.1 \\
\hline \multicolumn{3}{|l|}{ Annual income pre-DHOS } \\
\hline$<\$ 30000$ & 939 & 32.9 \\
\hline$\$ 30001-\$ 60000$ & 664 & 23.3 \\
\hline$\$ 60001-\$ 90000$ & 508 & 17.8 \\
\hline$\$ 90001+$ & 478 & 16.8 \\
\hline Unknown & 263 & 9.2 \\
\hline Household size (individuals) & 3.6 & 1.5 \\
\hline \multicolumn{3}{|l|}{ Education } \\
\hline$<$ High school & 327 & 11.5 \\
\hline $\begin{array}{l}\text { High school graduate (or General } \\
\text { Equivalency Diploma (GED)) }\end{array}$ & 785 & 27.5 \\
\hline $\begin{array}{l}\text { Vocational/Technical/Community/ } \\
\text { Some college }\end{array}$ & 865 & 30.3 \\
\hline College graduate & 805 & 28.2 \\
\hline Unknown & 70 & 2.4 \\
\hline
\end{tabular}

Employment

\begin{tabular}{lrc} 
Full time & 1225 & 43.0 \\
Part-time & 306 & 10.7 \\
Unemployed & 1224 & 42.9 \\
Other & 28 & 1.0 \\
Unknown & 69 & 2.4 \\
Health insurance & & \\
None & 446 & 15.6 \\
Private & 1074 & 37.7 \\
\hline & & Continued
\end{tabular}

Table 2 Continued

\begin{tabular}{lrr}
\hline & N & \multicolumn{1}{c}{$\%$} \\
\hline & Mean & \multicolumn{1}{c}{ SD } \\
\hline Medicare/Medicaid only & 405 & 14.2 \\
Multiple & 797 & 27.9 \\
Other & 56 & 2.0 \\
Unknown & 74 & 2.6 \\
General health & & \\
Excellent & 304 & 10.7 \\
Very good & 920 & 32.3 \\
Good & 927 & 32.5 \\
\hline Fair & 532 & 18.6 \\
Poor & 162 & 5.7 \\
Unknown & 7 & 0.2 \\
\hline
\end{tabular}

Parish

\begin{tabular}{lrr}
\hline Jefferson & 489 & 17.2 \\
\hline Lafourche & 540 & 18.9 \\
\hline Orleans & 532 & 18.7 \\
\hline Plaquemines & 184 & 6.4 \\
\hline St Bernard & 192 & 6.7 \\
\hline St Mary & 385 & 13.5 \\
\hline Terrebonne & 530 & 18.6 \\
\hline Smoking status & & \\
\hline Never smoker & 1813 & 63.6 \\
\hline Current smoker & 561 & 19.7 \\
\hline Former smoker & 465 & 16.3 \\
\hline Unknown & 13 & 0.5 \\
\hline Body mass index & & \\
\hline$<18.5$ (underweight) & 25 & 0.9 \\
\hline 18.5-24.9 (normal weight) & 737 & 25.8 \\
\hline 25.0-29.9 (overweight) & 828 & 29.0 \\
\hline 30.0-34.9 (class I obesity) & 574 & 20.1 \\
\hline 35.0-39.9 (class II obesity) & 337 & 11.8 \\
\hline$\geq 40.0$ (class III obesity) & 293 & 10.3 \\
\hline Unknown & 58 & 2.0 \\
\hline Prior disaster experience & & \\
\hline Yes & 2848 & 99.9 \\
\hline No & 3 & 0.1 \\
\hline Unknown & 1 & 0.0 \\
\hline Number of children (<18years) at home & & \\
\hline 0 & 571 & 20.0 \\
\hline 1 & 311 & 10.9 \\
\hline 3+ & & 42.9 \\
\hline
\end{tabular}

DHOS, Deepwater Horizon Oil Spill; WaTCH, Women and Their Children's Health. 
less than a college degree, and $43 \%$ reported working full time. Slightly over 5\% reported poor health, and $15 \%$ reported not having any health insurance. Participants were also relatively evenly distributed between five of the seven coastal parishes; Plaquemines and St Bernard parishes proportionally yielded fewer respondents, reflecting the smaller size and lower density of their parish populations.

\section{DHOS exposure}

After evaluating the fit indices and interpretability of each factor solution, a two-factor solution was found to have the best fit, explaining approximately $57 \%$ of the variance. Model fit statistics from the confirmatory factor analysis revealed there was an acceptable fit to the data for this two-factor solution $\left(\chi^{2}=116.11, \mathrm{p}<0.01\right.$; Comparative Fit Index $(\mathrm{CFI})=0.97$; Tucker-Lewis Index $(\mathrm{TLI})=0.96$; Root Mean Square Error of Approximation (RMSEA): 0.035; $90 \%$ CI $(0.029$ to 0.041$))$. The first factor, consisting of items related to income loss, how hard participants were hit compared with others and the oil spill's influence on household finances, was labelled as economic exposure. The second factor, consisting of the other six items, was labelled as physical/environmental exposure. Within each factor, the binary responses to the questions included in that factor were summed to create an exposure score. The range of possible scores for the physical/environmental exposure factor was $0-6$, and the economic exposure factor $0-3$. Exposure scores within each factor were categorised into three groups: unexposed, low exposure and high exposure. An exposure score of 0 was defined as unexposed, and the cut-points for low and high exposure were determined by the median exposure score within that factor. The major items contributing to physical/environmental exposure consisted of reports that the spill had directly affected recreational activities (34\%), smelling the oil $(27 \%)$ and coming into physical contact with the oil in other ways $(22 \%)$.

Table 3 shows the distribution of the DHOS exposure items among the adult women, broken down by exposure

\section{Table 3 Economic and physical/environmental exposure to the Deepwater Horizon Oil Spill (DHOS)}

\begin{tabular}{|c|c|}
\hline Exposure to the DHOS & $\mathbf{N}(\%)$ \\
\hline \multicolumn{2}{|l|}{ Economic exposure } \\
\hline 1. Lost Household income due to employment disruption/closing of business because of oil spill & $743(26.1)$ \\
\hline 3. Oil spill had somewhat or very negative influence on $\mathrm{HH}$ financial situation & $1064(37.3)$ \\
\hline \multicolumn{2}{|l|}{ Physical/Environmental exposure } \\
\hline \multicolumn{2}{|l|}{ 5. Extent and frequency of smelling oil } \\
\hline No smell exposure & $1694(59.4)$ \\
\hline Any smell exposure & $1035(36.3)$ \\
\hline
\end{tabular}

Strength of smell

\begin{tabular}{|c|c|}
\hline Extremely & $121(4.2)$ \\
\hline Quite & $148(5.2)$ \\
\hline Moderately & $424(14.9)$ \\
\hline A little strong & $276(9.7)$ \\
\hline Not strong & $60(2.1)$ \\
\hline Don't know & $6(0.2)$ \\
\hline \multicolumn{2}{|l|}{ Frequency } \\
\hline All the time & $183(6.4)$ \\
\hline Most of the time & 279 (9.8) \\
\hline Some of the time & 417 (14.6) \\
\hline A little of the time & 141 (4.9) \\
\hline None of the time & $7(0.2)$ \\
\hline Don't know & $8(0.3)$ \\
\hline $\begin{array}{l}\text { 6. Came into physical contact with oil in other ways (eg, during home, recreation, hunting, fishing or other } \\
\text { activities) }\end{array}$ & $624(21.9)$ \\
\hline 7. Oil spill directly affected recreational hunting/fishing/other activities of household & $972(34.1)$ \\
\hline 8. Worked on any oil spill clean-up activities & $55(1.9)$ \\
\hline 9. Any property lost or damaged due to oil spill or clean-up & $72(2.5)$ \\
\hline
\end{tabular}


groupings determined through confirmatory factor analysis. A small percentage of women worked on the DHOS clean-up activities (2\%), had property that was lost or damaged due to the DHOS $(2.5 \%)$ or reported physical damage to the commercial fishing areas used by members of their household (7\%). The participants reported DHOS exposure as having an impact on their financial situation, with $37 \%$ reporting a negative or somewhat negative impact on household finances and 26\% reporting losing income due to disruption of employment or the closing of a business.

\section{Children demographic characteristics}

Six hundred and twenty-one children and their mothers completed a baseline child interview. Demographic and exposure characteristics of children in the WaTCH study are shown in table 4 . Children were interviewed on average 3.5 years after the DHOS. Fifty per cent of the children were female. Fifty per cent of the mothers reported their child's race as white, $40 \%$ black, $6 \%$ as other and approximately $4 \%$ did not report race. Forty per cent of the children reported being enrolled in grades $9-12,43.5 \%$ enrolled in grades $6-8,15.5 \%$ in grades $3-5 \%$ and $1.2 \%$ either other or unknown. Thirty-three per cent of the children's mothers reported a prespill annual household income less than \$30 000, $25 \%$ reported an income between $\$ 30001$ and $\$ 60000$, $20 \%$ between $\$ 60001$ and $\$ 90000$, and $20 \%$ reported a household income greater than or equal to $\$ 90001$.

\section{Home visit subcohort}

There were 1231 (43\%) women who completed a wave I telephone interview and who also completed a home visit that included a blood, saliva or urine sample. Table 5 describes the demographics for WaTCH participants who provided blood samples. Among these women, we observe a slightly higher proportion of women who self-reported their race as black, had a lower prespill household income and had less education than the full cohort who completed the wave I telephone interview.

\section{Follow-up (wave II) survey participation}

There were $2038(72 \%)$ adult women enrolled at baseline who completed the wave II follow-up interview. Four hundred and fifty-seven $(74 \%)$ of the enrolled children completed the wave II interview. Among the adult women who completed the interview, a higher proportion were black $(36 \%)$ and more likely to report lower income and lower education compared with women who completed the wave I interview. The children who completed the wave II interview were equally balanced with respect to gender and race, closely mirroring wave I children participants. Complete adult women and children participant characteristics are shown in Table 6.

\section{Strengths and limitations}

The WaTCH study was established to examine the physical and mental health outcomes associated with the DHOS in a large community-based population. Many prior studies investigating health effects of previous oil spills often had small sample sizes, were cross-sectional in nature or focused on a target population such as workers.

Enumeration of the population was a logistical challenge; there are no comprehensive resident lists available in Louisiana as there are, for example, in Massachusetts. ${ }^{41}$ We therefore relied on commercially available resident lists of women with available telephone numbers residing in our targeted geographical region. While we attempted to recruit identified women, contacting them was challenging as they often moved, changed phone numbers or terminated their landline phone. We investigated the use of cell phone sample frames, but in 2012 the availability of cell phone numbers linked to a geographical locale or person was neither operationally feasible nor economically viable. We used a commercial tracing service (Accurint) to attempt to locate sample frame members, but without social security as part of the sampling frame, this was limited in its utility. However, for the follow-up survey, when social security numbers were provided by participants, tracing them through this service was marginally improved. Recruitment was also impacted by the community perception of BP, news and media reports, potential litigation, and numerous other factors. Anecdotally, many individuals presented with research fatigue from being recruited for numerous studies of past hurricanes and other DHOS-related activities. It has been recognised that participation rates for epidemiological studies have been declining during the past few decades, with even steeper declines in recent years. ${ }^{42}$ This global decrease in participation rates more likely than not affected our participation. While lower participation rates themselves do not necessarily reflect a greater proclivity for bias, any difference in participants and non-participants should be recognised as a potential source of bias. We employed remuneration as described above, as well as a community engagement effort through our $\mathrm{CAB}$, to enhance recruitment of women and children into the study.

The largest challenge the study faced was determination of participants' exposure to either the oil per se or the oil spill's impact. In lieu of direct toxicological, biological or environmental measures, the WaTCH study used an indirect assessment of participants' economic, physical or environmental impact from the spill. As the vast majority of participants did not participate in the clean-up activities and did not report proximate contact with the oil, the opportunity for direct exposure was fairly low. The timing of the exposure assessment was also a substantial challenge. Given that the oil spill began in April 2010, funding was not awarded until the middle of 2011 and subject recruitment did not start until 2012, it was impossible to obtain objective prespill exposure and health outcome data. This is a recognised limitation and inherent challenge in almost all disaster research. ${ }^{434}$ Given disasters are ubiquitous and nearly impossible to predict, much 
Table 4 Demographic and exposure characteristics of children $(n=621)$ in the WaTCH study

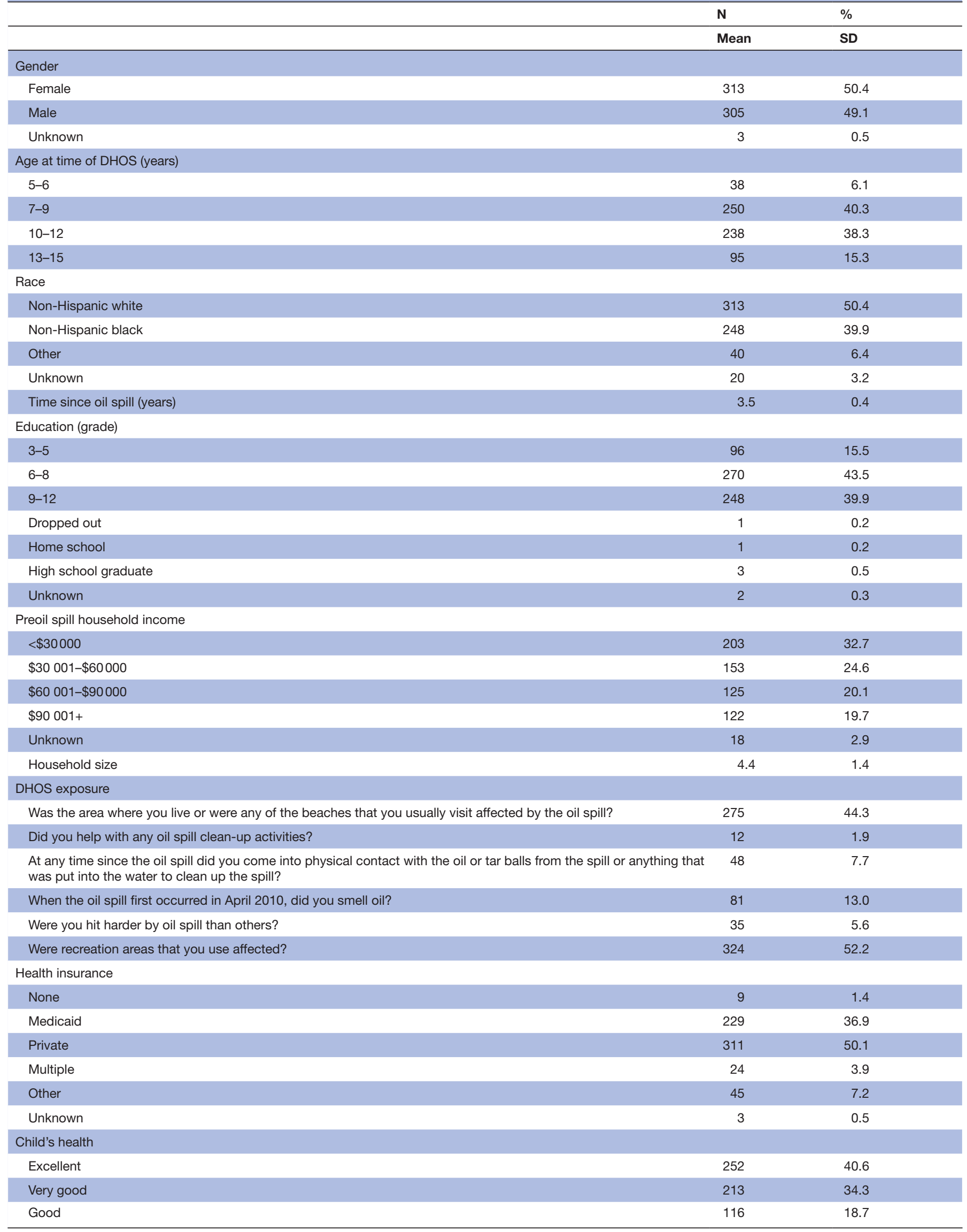


Table 4 Continued

\begin{tabular}{|c|c|c|}
\hline & $\mathbf{N}$ & $\%$ \\
\hline & Mean & SD \\
\hline Fair & 35 & 5.6 \\
\hline Unknown & 1 & 0.2 \\
\hline
\end{tabular}

DOHS, Deepwater Horizon Oil Spill; WaTCH, Women and Their Children's Health.

epidemiological research unfortunately transpires well after the fact. There is, therefore, a potential for recall bias, and for those with the least impact from the spill there is perhaps a greater likelihood to minimise or

\section{Table 5 Demographics for WaTCH participants with blood} samples

\begin{tabular}{|c|c|c|}
\hline & \multicolumn{2}{|c|}{ Wave 1} \\
\hline & $\mathbf{N}$ & $\%$ \\
\hline Total & 1058 & 100 \\
\hline \multicolumn{3}{|l|}{ Age (years) } \\
\hline $19-34$ & 189 & 17.9 \\
\hline $35-49$ & 534 & 50.5 \\
\hline $50-64$ & 237 & 22.4 \\
\hline $65+$ & 98 & 9.3 \\
\hline \multicolumn{3}{|l|}{ Marital status } \\
\hline Married/Living with partner & 638 & 60.3 \\
\hline Widow/Separated/Divorced & 225 & 21.3 \\
\hline Never married & 194 & 18.3 \\
\hline Unknown & 1 & 0.1 \\
\hline \multicolumn{3}{|l|}{ Race } \\
\hline Non-Hispanic black & 396 & 37.4 \\
\hline Non-Hispanic white & 587 & 55.5 \\
\hline Other & 61 & 5.8 \\
\hline Unknown & 14 & 1.3 \\
\hline \multicolumn{3}{|l|}{ Preoil spill household income } \\
\hline$<\$ 30000$ & 410 & 38.7 \\
\hline$\$ 30001-\$ 60000$ & 277 & 26.2 \\
\hline$\$ 60001-\$ 90000$ & 158 & 14.9 \\
\hline$\$ 90001+$ & 171 & 16.2 \\
\hline Unknown & 42 & 4.0 \\
\hline \multicolumn{3}{|l|}{ Education } \\
\hline$<$ High school & 141 & 13.3 \\
\hline $\begin{array}{l}\text { High school graduate/General Equivalency } \\
\text { Diploma (GED) }\end{array}$ & 298 & 28.2 \\
\hline Vocational/Community college/Some college & 343 & 32.4 \\
\hline College graduate & 276 & 26.1 \\
\hline \multicolumn{3}{|l|}{ Employment } \\
\hline Full time & 416 & 39.3 \\
\hline Part-time & 120 & 11.3 \\
\hline Unemployed & 505 & 47.7 \\
\hline Other & 16 & 1.5 \\
\hline Unknown & 1 & 0.1 \\
\hline
\end{tabular}

WaTCH, Women and Their Children's Health. trivialise exposure, or conversely to over-report exposure and health effects. Furthermore, the self-reported nature of exposure measurement enhances opportunity for misclassification of exposure. Nonetheless, the exposure questions were standardised, brief and fairly easy to recall in order to better estimate exposure. Additional efforts are underway to correlate and corroborate subjects' exposure with external reference data, such as spatiotemporal environmental measures collected by the state of Louisiana, BP and the Environmental Protection Agency, among others. Information on health and other outcomes was also self-reported and collected 2-3 years after the spill. As with recruitment, symptom reporting may have been influenced by media attention, litigation advertisements and community activism. While we tried to tie outcomes to calendar time in order to minimise association with the DHOS, and therefore mitigate a potential information bias, respondents often tied things together as there was no negating the fact that this was a study to examine health effects associated with the DHOS.

Assessment of the impact of disasters on health serves many purposes, ranging from small surveys designed to target and provide services in response to an event, to large-scale studies intended to examine and estimate the impact and long-term health effects of a disaster. The challenge with implementing these latter studies such as ours is they are more resource-intensive and require a longer start-up time and a more extended period of follow-up and analysis. ${ }^{45}$ Further, identifying those directly impacted by the event is a challenge, and inclusion of those with little to no impact may mask potential smaller effects of the exposed population. Recent studies have been published suggesting that one of the long-lasting legacies of the DHOS is on the mental and behavioural health of the affected communities. ${ }^{25} 46-48$ Thus continued maintenance and follow-up of this cohort is critical to understand the long-term health consequences of the DHOS.

\section{Collaborations}

This is one of the largest community-based prospective cohort studies funded to date by the NIEHS extramural research division with respect to any oil spill. Epidemiological disaster research is replete with logistical and ethical challenges with respect to funding, development and implementation of efforts to collect data in a timely manner. Nonetheless, the WaTCH study employed a robust design with validated and repeated outcome 
Table 6 Demographics of adult women $(n=2038)$ and children $(n=457)$ who completed the follow-up wave Il survey. ${ }^{*}$ These categories are exclusive to the child population

\begin{tabular}{|c|c|c|}
\hline & Women & Children \\
\hline Age (years) & $\mathrm{N}(\%)$ & $\mathrm{N}(\%)$ \\
\hline $10-12$ & & $58(12.7)$ \\
\hline $13-15$ & & $180(39.4)$ \\
\hline $16-17$ & & $123(26.9)$ \\
\hline $18-20$ & & $96(21.0)$ \\
\hline $18-35$ & $272(13.4)$ & \\
\hline $36-64$ & $1508(74.0)$ & \\
\hline $65+$ & $258(12.7)$ & \\
\hline \multicolumn{3}{|l|}{ Gender } \\
\hline Female & $2038(100)$ & $228(49.9)$ \\
\hline Male & & $229(50.1)$ \\
\hline \multicolumn{3}{|l|}{ Race } \\
\hline Non-Hispanic black & $740(36.3)$ & $190(41.6)$ \\
\hline Non-Hispanic white & $1149(56.4)$ & $231(50.5)$ \\
\hline Other & $127(6.2)$ & $28(6.1)$ \\
\hline Unknown & $22(1.1)$ & $8(1.7)$ \\
\hline \multicolumn{3}{|l|}{ Current household income } \\
\hline$<\$ 30000$ & $811(39.8)$ & $147(32.2)$ \\
\hline$\$ 30001-\$ 60000$ & $481(23.6)$ & $111(24.3)$ \\
\hline$\$ 60001-\$ 90000$ & $287(14.1)$ & $92(20.1)$ \\
\hline$\$ 90000+$ & 403 (19.8) & $98(21.4)$ \\
\hline Unknown & $56(2.8)$ & $9(2.0)$ \\
\hline \multicolumn{3}{|l|}{ Education } \\
\hline $3-5^{\star}$ grade & - & $2(0.4)$ \\
\hline $6-8^{*}$ grade & - & $134(29.3)$ \\
\hline $9-12^{*}$ grade & - & $238(52.1)$ \\
\hline Home school* & - & $1(0.2)$ \\
\hline$<$ High school & $232(11.4)$ & 0 \\
\hline High school graduate (or General Equivalency Diploma (GED)) & $573(28.1)$ & $18(3.9)$ \\
\hline Vocational/Community/Some college & $616(30.2)$ & $61(13.3)$ \\
\hline College graduate & $616(30.2)$ & - \\
\hline Unknown & $1(0.1)$ & $3(0.7)$ \\
\hline \multicolumn{3}{|l|}{ Deepwater Horizon Oil Spill exposure } \\
\hline Live in or visit affected areas & $1450(71.2)$ & $207(45.3)$ \\
\hline Lost $\mathrm{HH}$ income & $521(25.6)$ & - \\
\hline Hit harder by oil spill & $127(6.2)$ & $23(5.0)$ \\
\hline Somewhat/Very negative effect on $\mathrm{HH}$ & $752(36.9)$ & - \\
\hline Damage to commercial fisheries & $141(6.9)$ & - \\
\hline Smelled oil & $758(37.2)$ & $65(14.2)$ \\
\hline Physical contact with oil & $437(21.4)$ & $40(8.8)$ \\
\hline Recreation areas affected & $706(34.6)$ & $233(51.0)$ \\
\hline Oil spill clean-up & $36(1.8)$ & $9(2.0)$ \\
\hline Property lost or damaged & $50(2.4)$ & - \\
\hline
\end{tabular}

measurements in a prospective manner. It provides a powerful framework to study physical and mental health effects in an especially vulnerable population subjected to repeated natural and technological disasters. The population is racially diverse and includes participants from communities and demographics often not 
included in typical epidemiological cohort studies. The WaTCH study provides a unique opportunity to address important public health concerns in an understudied population. Collaborations are encouraged, although data sets are not currently publicly available. Potential collaborators are encouraged to contact the author directly via email. Presently wave I data have been cleaned and are available for analyses. Wave II data are in the process of undergoing data harmonisation.

\section{Author affiliations}

'Department of Epidemiology, Louisiana State University Health Sciences Center School of Public Health, New Orleans, LA, USA

${ }^{2}$ Department of Public Health Sciences, University of Virginia, Charlottesville, VA, USA

${ }^{3}$ Office of Research and Development/National Exposure Research Laboratory, US Environmental Protection Agency, Research Triangle Park, NC, USA

${ }^{4}$ Department of Epidemiology, Rollins School of Public Health, Emory University, Atlanta, GA, USA

${ }^{5}$ Program on Population Impact, Recovery, and Resiliency, New York University College of Global Public Health, New York, NY, USA

${ }^{6}$ Department of Environmental and Occupational Health Sciences, Louisiana State University Health Sciences Center School of Public Health, New Orleans, LA, USA ${ }^{7}$ Department of Biostatistics, Louisiana State University Health Sciences Center School of Public Health, New Orleans, LA, USA

Acknowledgements The authors wish to thank the study participants, community advisory board and the WaTCH study staff for their support and contributions to this endeavour.

Contributors ESP, ALR, DMA, DH, ETHF and EJT participated in the formulation of study aims, design and analytic methods. MHB, LCP, SMS, SG and KP participated in data acquisition. MMB and EO participated in data management and statistical analysis. ESP drafted the manuscript, and ALR, ETHF, DH and EJT critically read, revised, reviewed and approved the final manuscript.

Funding This research was funded by the National Institute of Environmental Health Sciences (1U01ES021497) with additional support from the Louisiana State University Health Science Center School of Public Health's Epidemiology Department and Office of Research.

Competing interests None declared.

Patient consent Obtained.

Ethics approval Louisiana State University Health Sciences Center-New Orleans IRB.

Provenance and peer review Not commissioned; externally peer reviewed.

Data sharing statement The researchers associated with this study are not aware of any reasons which might prohibit the sharing and reuse of the data being submitted following thorough application of all policies and procedures subject to LSUHSC-IRB review and deidentification. An end user data use agreement will be required for accessing the data. The user will not have access to the original data or the original codebook that is securely stored at the LSUHSC School of Public Health. They agree to not share this data with others not under their direct supervision and will destroy the data at the conclusion of their analysis. Copies of analytic data sets will be returned to the WaTCH study for archival purposes. Waves I and II have been cleaned and are available for analyses. Collaborations are encouraged, although data sets are not currently publicly available. Potential collaborators are encouraged to contact the author (epete1@Isuhsc.edu) directly via email.

Open Access This is an Open Access article distributed in accordance with the Creative Commons Attribution Non Commercial (CC BY-NC 4.0) license, which permits others to distribute, remix, adapt, build upon this work non-commercially, and license their derivative works on different terms, provided the original work is properly cited and the use is non-commercial. See: http://creativecommons.org/ licenses/by-nc/4.0/

(c) Article author(s) (or their employer(s) unless otherwise stated in the text of the article) 2017. All rights reserved. No commercial use is permitted unless otherwise expressly granted.

\section{REFERENCES}

1. Levy BS, Nassetta WJ. The adverse health effects of oil spills: a review of the literature and a framework for medically evaluating exposed individuals. Int J Occup Environ Health 2011;17:161-8.

2. Graham B, Reilly WK, Beinecke F, et al; Deep water: the Gulf Oil disaster and the Future of Offshore Drilling. National Commission on the BP Deepwater Horizon Oil spill and Offshore Drilling (U.S, 2011. doi.

3. Griffiths SK. Oil release from Macondo well MC252 following the Deepwater Horizon accident. Environ Sci Technol 2012;46:5616-22.

4. Michel J, Owens EH, Zengel S, et al. Extent and degree of shoreline oiling: deepwater Horizon oil spill, Gulf of Mexico, USA. PLoS One 2013;8:e65087.

5. Goldstein BD, Osofsky HJ, Lichtveld MY. The Gulf oil spill. N Engl J Med 2011;364:1334-48.

6. Biello D. Is using dispersants on the BP Gulf Oil spill fighting Pollution with Pollution? Sci. Am. 2010 http://www.scientificamerican. com/article/is-using-dispersants-fighting-pollution-with-pollution/ (accessed 12 Sep2015).

7. Jernelöv A. The threats from oil spills: now, then, and in the future. Ambio 2010;39:353-66 http://www.ncbi.nlm.nih.gov/pubmed/ 21053719.

8. Aguilera F, Méndez J, Pásaro E, et al. Review on the effects of exposure to spilled oils on human health. J App/ Toxicol 2010;30:n/ a-301.

9. Rung AL, Oral E, Fontham E, et al. Mental health impact of the Deepwater Horizon Oil Spill among wives of Clean-up Workers. Epidemiology 2015;26:e44-e46.

10. Lichtveld M, Sherchan S, Gam KB, et al. The Deepwater Horizon Oil spill through the Lens of Human Health and the Ecosystem. Curr Environ Health Rep 2016;3:370-8.

11. Solomon GM, Janssen S. Health effects of the Gulf oil spill. JAMA 2010;304:1118-9.

12. Laffon B, Pásaro E, Valdiglesias V. Effects of exposure to oil spills on human health: updated review. J Toxicol Environ Health B Crit Rev 2016;19:105-28

13. Goldmann E, Galea S. Mental health consequences of disasters. Annu Rev Public Health 2014;35:169-83.

14. Tosevski DL, Milovancevic MP. Stressful life events and physical health. Curr Opin Psychiatry 2006;19:184-9.

15. Pearlin LI, Schieman S, Fazio EM, et al. Stress, health, and the life course: some conceptual perspectives. J Health Soc Behav 2005;46:205-19.

16. Cohen S, Janicki-Deverts D, Miller GE. Psychological stress and disease. JAMA 2007;298:1685-7.

17. Gould DW, Teich JL, Pemberton MR, et al. Behavioral health in the gulf coast region following the Deepwater Horizon oil spill: findings from two federal surveys. J Behav Health Serv Res 2015;42:6-22.

18. Drescher CF, Schulenberg SE, Smith CV. The Deepwater Horizon Oi spill and the Mississippi Gulf Coast: mental health in the context of a technological disaster. Am J Orthopsychiatry 2014;84:142-51.

19. Ritchie LA, Gill DA, Picou JS. The BP disaster as an Exxon Valdez Rerun. Contexts 2011;10:30-5.

20. Mayer B, Running K, Bergstrand K, Compensation BK. Compensation and Community Corrosion: perceived inequalities, Social Comparisons, and competition following the Deepwater Horizon Oil spill. Sociol Forum 2015;30:369-90.

21. Nelson JR, Bauer JR, Rose K. Assessment of Geographic setting on oil spill impact severity in the United States - <l>Insights from two key spill events in support of risk Assessment for Science-Based Decision making $</ l>$. Journal of Sustainable Energy Engineering 2014;2:152-65.

22. Gill DA, Picou JS, Ritchie LA. The Exxon Valdez and BP Oil spills: a comparison of initial social and psychological impacts. Am Behav Sci 2012;56:3-23.

23. Palinkas L, Downs M, Petterson J, et al. Social, Cultural, and psychological impacts of the Exxon Valdez Oil spill. Hum Organ 1993;52:1-13.

24. Rodríguez-Trigo G, Zock JP, Pozo-Rodríguez F, et al. Health changes in fishermen 2 years after clean-up of the Prestige oil spill. Ann Intern Med 2010;153:489-98.

25. Grattan LM, Roberts S, Mahan WT, et al. The early psychological impacts of the Deepwater Horizon oil spill on Florida and Alabama communities. Environ Health Perspect 2011;119:838-43.

26. Rung AL, Gaston S, Oral E, et al. Depression, mental distress, and domestic conflict among Louisiana Women exposed to the Deepwater Horizon Oil spill in the WaTCH Study. Environ Health Perspect 2016;124:1429-35.

27. Peres LC, Trapido E, Rung AL, et al. The Deepwater Horizon Oil spill and Physical Health among Adult women in Southern Louisiana: the 
women and their Children's Health (WaTCH) Study. Environ Health Perspect 2016:124:1208-13.

28. Osofsky HJ, Osofsky JD, Hansel TC. Deepwater Horizon Oil spill : mental Health Effects. Disaster Med Public Health Prep 2011;5:280-6.

29. Kwok RK, Engel LS, Miller AK, et al. The GuLF STUDY: a prospective study of Persons involved in the Deepwater Horizon Oil spill response and Clean-Up. Environ Health Perspect 2017;125:570-8.

30. Ha M, Jeong WC, Lim M, et al. Children's Mental Health in the Area Affected by the Hebei Spirit Oil Spill Accident. Environ Health Toxicol 2013;28:e2013010.

31. Shultz JM, Walsh L, Garfin DR, et al. The 2010 Deepwater Horizon oil spill: the trauma signature of an ecological disaster. J Behav Health Serv Res 2015;42:58-76.

32. IOM. Institute of Medicine). Research Priorities for Assessing Health Effects from the Gulf of Mexico Oil spill: a Letter Report. The National Academies Press 2010 http://www.ncbi.nlm.nih.gov/pubmed/ 21391342.

33. Hertz-Picciotto I, Epidemiology E. In: Rothman K, Greenland S, Lash T, eds. Modern Epidemiology. Philadelphia:: Lippincott Williams \& Wilkins 2008:598-619.

34. Palinkas LA, Petterson JS, Russell J, et al. Community patterns of psychiatric disorders after the Exxon Valdez oil spill. Am J Psychiatry 1993;150:1517-23.

35. Deepwater Horizon Research Consortia. https://www.niehs.nih.gov/ research/supported/centers/gulfconsortium/ (accessed 26 Jan2017).

36. Wolf LE, Patel MJ, Williams Tarver BA, et al. Certificates of Confidentiality: protecting Human Subject Research Data in Law and Practice. J Law Med Ethics 2015;43:594-609.

37. Harris PA, Taylor R, Thielke R, et al. Research electronic data capture (REDCap)--a metadata-driven methodology and workflow process for providing translational research informatics support. J Biomed Inform 2009;42:377-81.
38. Hamilton CM, Strader LC, Pratt JG, et al. The PhenX Toolkit: get the most from your measures. Am J Epidemiol 2011;174:253-60.

39. Andresen EM, Malmstrom TK, Schootman M, et al. Observer ratings of neighborhoods: comparison of two methods. BMC Public Health 2013;13:1024.

40. The American Association for Public Opinion Research. Standard definitions: final dispositions of case codes and Outcome Rates for surveys. 8th edition, 2015.

41. Bohlke K, Harlow BL, Cramer DW, et al. Evaluation of a population roster as a source of population controls: the Massachusetts Resident lists. Am J Epidemiol 1999;150:354-8 http://www.ncbi.nlm. nih.gov/pubmed/10453811.

42. Galea S, Tracy M. Participation rates in epidemiologic studies. Ann Epidemiol 2007;17:643-53.

43. Lurie N, Manolio T, Patterson AP, et al. Research as a part of public health emergency response. $N$ Engl J Med 2013;368:1251-5.

44. Miller A, Yeskey K, Garantziotis S, et al. Integrating Health Research into disaster response: the New NIH disaster Research Response Program. Int J Environ Res Public Health 2016;13:676-12.

45. Teich JL, Pemberton MR. Epidemiologic studies of Behavioral Health following the Deepwater Horizon Oil spill: limited impact or limited ability to measure? J Behav Heal Serv Res 2014:1-9.

46. Rosenberg L, Ligenza $L$. The deepwater horizon oil spill and ongoing mental health impact. J Behav Health Serv Res 2015;42:1-2.

47. Rung AL, Oral E, Fontham E, et al. Mental Health Impact of the Deepwater Horizon Oil spill among wives of Clean-up Workers. Epidemiology 2015;26:e44-e46.

48. Morris JG, Grattan LM, Mayer BM, et al. Psychological responses and resilience of people and communities impacted by the deepwater horizon oil spill. Trans Am Clin Climatol Assoc 2013;124:191-201 http://www.ncbi.nlm.nih.gov/pubmed/23874022. 